\title{
Blood RNA biomarker panel detects both left- and right-sided colorectal neoplasms: a case-control study
}

\author{
Samuel Chao ${ }^{1}$, Jay Ying ${ }^{1}$, Gailina Liew ${ }^{1}$, Wayne Marshall ${ }^{1,2}$, Choong-Chin Liew ${ }^{1 *}$ and Robert Burakoff ${ }^{3}$
}

\begin{abstract}
Background: Colonoscopy is widely regarded to be the gold standard for colorectal cancer (CRC) detection. Recent studies, however, suggest that the effectiveness of colonoscopy is mostly confined to tumors on the left side of the colon (descending, sigmoid, rectum), and that the technology has poor tumor detection for right-sided (cecum, ascending, transverse) lesions. A minimally invasive test that can detect both left-sided and right-sided lesions could increase the effectiveness of screening colonoscopy by revealing the potential presence of neoplasms in the right-sided "blind spot".

Methods: We previously reported on a seven-gene, blood-based biomarker panel that effectively stratifies a patient's risk of having CRC. For the current study, we assessed the effectiveness of the seven-gene panel for the detection of left- and right-sided CRC lesions. Results were evaluated for 314 patients with CRC (left-sided: TNM I, 65; TNM II, 57; TNM III, 60; TNM IV, 17; unknown, 9. right-sided: TNM I, 28; TNM II, 29; TNM III, 38; TNM IV, 12; unknown, 1 and including two samples with both left and right lesions) and 328 control samples. Blood samples were obtained prior to clinical staging and therapy. Most CRC subjects had localized disease (stages I and II, 58\%); regional (stage III) and systemic (stage IV) disease represented 32\% and 9\%, respectively, of the study population.

Results: The panel detected left-sided $(74 \%, 154 / 208)$ and right-sided $(85 \%, 92 / 108)$ lesions with an overall sensitivity of $78 \%$ (215/316) at a specificity of $66 \%$ (215/328). Treatable cancer (stages I to III) was detected with left-sided lesion sensitivity of 76\% (138/182) and right-sided sensitivity of 84\% (80/95).

Conclusion: This seven-gene biomarker panel detected right-sided CRC lesions across all cancer stages with a sensitivity that is at least equal to that for left-sided lesions. This study supports the use of this panel as the basis for a patient-friendly, blood-based test that can be easily incorporated into a routine physical examination in advance of colonoscopy to provide a convenient companion diagnostic and a pre-screening alert, ultimately leading to enhanced CRC screening effectiveness.
\end{abstract}

Keywords: Colorectal cancer, Biomarkers, Microarray, Blood gene expression, Colonoscopy

\section{Background}

Colorectal cancer (CRC) is the third most common cancer and the second most common cause of cancer deaths in the United States and Canada. The disease is expected to be diagnosed in approximately 142,820 Americans in 2013, and an estimated 50,830 people are expected to die of CRC in that year [1]. In Canada an estimated 23,900

\footnotetext{
* Correspondence: cliew@genenews.com

'GeneNews Ltd, 2 East Beaver Creek Road, Building 2, Richmond Hill, Ontario, Canada

Full list of author information is available at the end of the article
}

Canadians will be diagnosed with CRC in 2013, and 9,200 Canadians will die of the disease [2].

In the National Polyp Study, colonoscopy with adenoma removal was associated with a reduction in CRC as high as $90 \%$ [3]. Recently, however, several reports have questioned whether colonoscopy as practiced in the community reduces CRC and mortality to the same degree as that reported by highly specialized cancer centers [4-7].

Studies have found that although colonoscopy effectiveness is high for lesions that arise on the left side of the colon, the procedure fails to confer similar levels of

\section{Biomed Central}


protection from CRC incidence and mortality in rightsided lesions. In 2009, a case-control study of colonoscopy in Ontario, Canada, reported that although the procedure reduced mortality from left-sided lesions by about $40 \%$, no reduction in deaths was evident when CRC originated in the right colon [4]. Similarly, in a population-based retrospective analysis from Manitoba, colonoscopy found no reduction in CRC mortality in the case of proximal lesions [5]. A large German, statewide cross-sectional study of colonoscopy found the prevalence of advanced colorectal neoplasms strongly reduced by $67 \%$ in left-sided lesions, but this protection did not extend when the lesions were right-sided [6]. A later study by the same authors, which emphasized high-quality colonoscopy, found the procedure to be associated with a reduced risk of $56 \%$ for right colonic lesions, which is an improvement over earlier reports, but is less than the $84 \%$ reduced risk for CRC the authors observed for left colonic lesions [7].

A number of suggestions have been advanced to explain why colonoscopy may be less effective in the right colon than in the left. The technology is operatordependent and requires complete endoscopic evaluation, which is more difficult to complete in the right side of the colon. Bowel cleansing and preparation for colonoscopy may be less adequate on the right side, making lesions more difficult to visualize. Nonpolypoid flat or depressed lesions are more prevalent in the right than in the left side of the colon, and these are more challenging to identify and remove [8]. There may also be differences in biology between proximal and distal lesions; for example, distal and proximal CRCs show genetic and molecular differences [9].

We previously reported a seven-gene, blood-based biomarker panel for CRC detection [10]. For this current study, we hypothesize that this gene panel, which is a blood-based test, not dependent on localization, preparation or operator technique, can provide a non-biased method for detecting CRC arising in either the right or the left side of the colon.

The test is intended as a pre-screening tool and convenient companion diagnostic test to help those patients who are averse to colonoscopy and to the fecal occult blood test to make an informed decision based on their individual molecular profile. Because of its narrow focus, the test is not expected to alter clinical practice for patients who comply with recommended screening schedules.

\section{Methods}

Sample collection procedures and details of methodology for identification of the seven-gene blood-based biomarker panel for CRC were reported in our earlier study [10]. Briefly, 9,199 blood samples were taken from screening colonoscopy subjects at twenty-four centers located in the Greater Toronto Area and surrounding regions and in the United States, between March 2005 and March 2008. Uniformity of collection procedures at the different sites was ensured by the use of identical study protocols, uniform training of personnel, and periodic site monitoring. Informed consent was obtained according to protocols approved by the Research Ethics Board of each of the participating twenty-four clinics and hospitals.

The low incidence of CRC in the colonoscopy screening population made it necessary to recruit additional patients from cancer clinics in Toronto. In these cases, blood samples were collected prior to any treatment, including surgery. Patients enrolled in colonoscopy clinics provided blood prior to colonoscopy. Samples were categorized following review of pathology reports.

Case samples comprised blood samples taken from colonoscopy-confirmed CRC patients who had not undergone CRC treatment. Institutional pathologists determined cancer stage according to the American Joint Committee on Cancer (AJCC) Tumour, Node, and Metastases (TNM) staging system [11]. Controls comprised samples from subjects with no pathology at colonoscopy.

The qRT-PCR training set was composed of 112 wellcharacterized CRC and 120 control samples (total $=232$ ) taken from the population described above. Cancer and control samples were matched for age, sex, body mass index (BMI) and ethnicity.

An independent blind test set was composed of 410 average-risk subjects following colonoscopy (202 CRC/ 208 control). Average risk was defined as follows: subjects aged $\geq 50$ with no cancer or chemotherapy history, no previous record of colorectal disease (adenomatous polyps, CRC or inflammatory bowel disease) and no first-degree relatives with CRC. Cancer and control samples were matched for sex, BMI and ethnicity. The average age of patients was 3.6 years older than that of control subjects.

Most of the patients and controls who provided samples for qRT-PCR experiments had one or multiple comorbidities, most commonly, hypertension, hypercholesterolemia, diabetes, arthritis, anemia and allergies. More than $56 \%$ of the CRC samples were diagnosed with early stage I and II CRC and 32\% with stage III cancer. (Table 1) This means that approximately $90 \%$ of cases were potentially treatable CRC patients, which increases the practical value of the test.

\section{Blood collection and RNA isolation}

Samples were collected in PAXgene ${ }^{\mathrm{Tm}}$ tubes (PreAnalytiX) and processed according to the manufacturer's Blood RNA Kit protocol. RNA quality for all samples was assessed using a 2100 Bioanalyzer RNA 6000 Nano Chip (Agilent Technologies). All samples met quality criteria: RIN $\geq 7.0 ; 28 S: 18 S$ rRNA ratio $\geq 1.0$ and a validated 
Table 1 Available samples

\begin{tabular}{|c|c|c|c|c|c|c|}
\hline \multirow{2}{*}{$\begin{array}{l}\text { Sample \# } \\
\text { Category }\end{array}$} & \multicolumn{2}{|c|}{ Training } & \multicolumn{2}{|c|}{ Test } & \multicolumn{2}{|c|}{ Combined } \\
\hline & Left & Right & Left & Right & Left & Right \\
\hline TNM I & 19 & 12 & 46 & 16 & 65 & 28 \\
\hline TNM II & 20 & 11 & 37 & 18 & 57 & 29 \\
\hline TNM III & 21 & 13 & 39 & 25 & 60 & 38 \\
\hline TNM IV & 7 & 5 & 10 & 7 & 17 & 12 \\
\hline Unknown & 5 & 1 & 4 & 0 & 9 & 1 \\
\hline All Stages & 72 & 42 & 136 & 66 & 208 & 108 \\
\hline Control & \multicolumn{2}{|c|}{120} & \multicolumn{2}{|c|}{208} & \multicolumn{2}{|c|}{328} \\
\hline
\end{tabular}

NB Two training samples have both left and right cancer.

Agilent bioanalyzer scan. RNA quantity was determined by absorbance at $260 \mathrm{~nm}$ in a DU-640 Spectrophotometer (Beckman Coulter).

Quantitative reverse-transcriptase polymerase chain reaction One microgram of RNA was reverse-transcribed into singlestranded complementary DNA (cDNA) using High Capacity cDNA Reverse Transcription Kit (Applied Biosystems) in a $20 \mu \mathrm{L}$ reaction. For PCR, 20ng cDNA was mixed with QuantiTect ${ }^{\circ}$ Probe PCR Master Mix (Qiagen), and TaqMan ${ }^{\circ}$ dual-labeled probe and primers corresponding to the gene of interest and reference gene, in a $25 \mu \mathrm{L}$ reaction volume. PCR amplification was performed using a 7500 Real-Time PCR System (Applied Biosystems). Each sample was tested in duplicate reactions on the same PCR plate. The run results were subjected to quality control processes, and failed samples were repeated. Samples that failed a second time were excluded from the analysis.

For the blind test set, first, we selected samples with disease status known (in order to balance the sample groups and avoid biases in clinical and demographic characteristics). Selected samples were then randomized and assigned blinded identification prior to the experiment, and data analysis was performed by scientists blinded to the disease status.

\section{The seven-gene panel}

Details of the characterization and validation of the sevengene panel to identify CRC have been described previously [10]. In that study a seven-gene panel (ANXA3, CLEC4D, LMNB1, PRRG4, TNFAIP6, VNN1, IL2RB) discriminated $C R C$ in the training set [area under the receiveroperating-characteristic curve (AUC ROC), 0.80; accuracy, 73\%; sensitivity, $82 \%$; specificity $64 \%$ ]. The independent blind test set confirmed performance (AUC ROC, 0.80; accuracy, $71 \%$; sensitivity, $72 \%$; specificity, $70 \%$ ).

For the present study we re-analyze the previously reported data in order to determine the ability of the seven gene panel not only to identify the presence of CRC but also to identify cancer stages and left- and right-sided colon cancer.

\section{Results}

The training set data was used to determine the best coefficients for a logistic regression model using 6 ratios of the 7 genes most discriminative for CRC. This model was then used to predict the CRC risk for the test set samples.

Breaking the data down by cancer stages, we were able to find the same predictive values for left- and rightsided cancers as for CRC detection as in the original paper (Table 2).

In this study, CRC detection sensitivity was generally higher for right-sided cancer except in the case of TNM stage I in the test set. However, this finding may be simply a sampling issue. To resolve this question, we combined all training and test set samples and performed 2-fold cross validation, iterated 1000 times. This process partitions the samples into 2 halves such that that the coefficients of the model are fitted to the training half and applied to the test half.

The results for all the test halves after 1000 permutations represent a less biased estimate of the performance of the gene panel. As expected, the lower sensitivity for right-sided TNM I as compared with left-sided TNM I cancers is no longer observed in the cross-validated results. Overall, right-sided lesions are detected at a higher sensitivity than left-sided lesions; however, there are fewer right-sided samples, so the observed higher sensitivity may not be statistically significant. As can be seen from the box and whisker plots of the distribution of the prediction scores, the $98 \%$ confidence intervals show considerable overlap both across all TNM stages and for left and right sided cancers (Figure 1).

The panel detected left-sided $(75 \%, 156 / 208)$ and rightsided $(85 \%, 92 / 108)$ lesions with an overall sensitivity of

Table 2 Correct call rate

\begin{tabular}{|c|c|c|c|c|c|c|}
\hline \multirow[b]{3}{*}{ Stage } & \multirow{2}{*}{\multicolumn{2}{|c|}{ Training }} & \multirow{2}{*}{\multicolumn{2}{|c|}{ Test }} & \multirow{2}{*}{\multicolumn{2}{|c|}{$\begin{array}{c}\text { 1000X 2-Fold } \\
\text { Cross validation }\end{array}$}} \\
\hline & & & & & & \\
\hline & Left & Right & Left & Right & Left & Right \\
\hline \multirow{2}{*}{ TNM I } & $63 \%$ & $92 \%$ & $61 \%$ & $44 \%$ & $67 \%$ & $66 \%$ \\
\hline & $(12 / 19)$ & $(11 / 12)$ & $(28 / 46)$ & $(7 / 16)$ & $(43.5 / 65)$ & $(18.6 / 28)$ \\
\hline \multirow{2}{*}{ TNM II } & $70 \%$ & $91 \%$ & $81 \%$ & $89 \%$ & $79 \%$ & $89 \%$ \\
\hline & $(14 / 20)$ & $(10 / 11)$ & $(30 / 37)$ & $(16 / 18)$ & $(45.0 / 57)$ & $(25.9 / 29)$ \\
\hline \multirow{2}{*}{ TNM III } & $86 \%$ & $100 \%$ & $74 \%$ & $84 \%$ & $83 \%$ & $90 \%$ \\
\hline & $(18 / 21)$ & $(13 / 13)$ & $(29 / 39)$ & $(21 / 25)$ & $(49.6 / 60)$ & $(34.3 / 38)$ \\
\hline \multirow{2}{*}{ TNM IV } & $86 \%$ & $100 \%$ & $50 \%$ & $100 \%$ & $66 \%$ & $100 \%$ \\
\hline & $(6 / 7)$ & $(5 / 5)$ & $(5 / 10)$ & $(7 / 7)$ & $(11.2 / 17)$ & $(12.0 / 12)$ \\
\hline \multirow{2}{*}{ Unknown } & $80 \%$ & $100 \%$ & $100 \%$ & $\mathrm{n} / \mathrm{a}$ & $80 \%$ & $100 \%$ \\
\hline & $(4 / 5)$ & $(1 / 1)$ & $(4 / 4)$ & $(0 / 0)$ & $(7.2 / 9)$ & $(1.0 / 1)$ \\
\hline \multirow{2}{*}{ All Stages } & $75 \%$ & $95 \%$ & $71 \%$ & $77 \%$ & $75 \%$ & $85 \%$ \\
\hline & $(54 / 72)$ & $(40 / 42)$ & $(96 / 136)$ & $(51 / 66)$ & (156.5/208) & $(91.8 / 108)$ \\
\hline Control & \multicolumn{2}{|c|}{$64 \%(77 / 120)$} & \multicolumn{2}{|c|}{$70 \%(145 / 208)$} & \multicolumn{2}{|c|}{$64 \%(210 / 328)$} \\
\hline
\end{tabular}




\section{X 2-Fold Cross Validation}

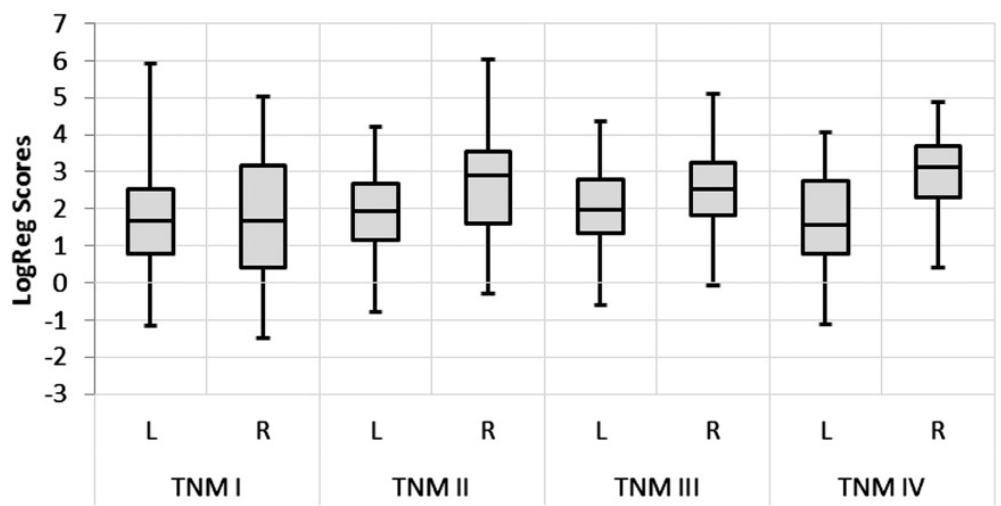

Figure 1 Distribution of prediction scores from 1000 iterations of 2 -fold cross-validation analysis. Boxes indicate the central 50 percentile with whiskers showing the extent of the 98 percentile.

$78 \%(248 / 316)$ at a specificity of $64 \%$ (210/328). Treatable cancer (stages I to III) was detected with a left-sided lesion sensitivity of $76 \%(138 / 182)$ and a right-sided sensitivity of $83 \%(79 / 95)$.

\section{Discussion}

In several studies we have shown that gene signatures obtained using blood mRNA can identify a variety of conditions occurring in various sites throughout the body, including heart failure [12], inflammatory bowel disease [13,14], psychiatric disorders [15-17] and various cancers [10,18-20]. These studies suggest that blood cells may act as "sentinels" that can mirror health or disease anywhere in the body. Blood transcriptomic signatures thus reflect molecular changes regardless of where they occur in the body.

We have also recently reported a blood test based on the performance characteristics of a seven-gene panel that enables us to assess a patient's current risk of having CRC [10]. As a blood test similar to other routine blood tests, the assay overcomes a number of reported limitations to patient acceptance of CRC screening using currently utilized tests. Such barriers include patients' fear of pain, inconvenience, unpleasantness, pre-procedure colon evacuation methods, the need to take time off work and to be sedated, risks such as bowel perforation, bleeding and other complications (for colonoscopy and other endoscopic methods) and patient embarrassment and beliefs that methods are unsanitary, unpleasant or inconvenient (fecal tests) [21-27]. By contrast, a simple, convenient blood test should encourage increased compliance with screening recommendations.

In this study we use the same seven-gene panel to address another issue limiting the effectiveness of colonoscopy: the right-sided bias observed in such technology.

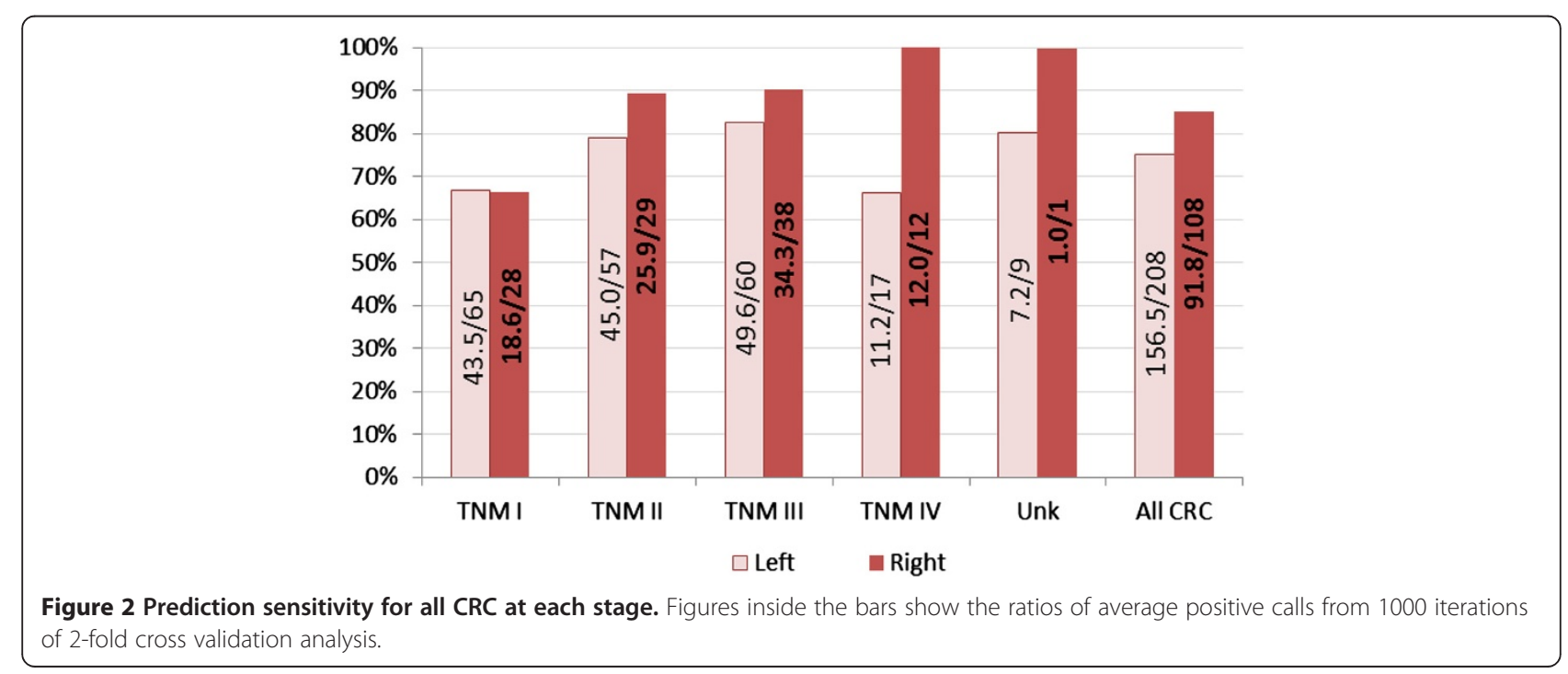


CRC can arise in either the right, proximal colon or the left, distal colon. The former includes the cecum, ascending colon, hepatic flexure and transverse colon, and the latter the descending and sigmoid colon and rectum. Colonoscopy tends to bias towards detection on the left side, for reasons both technical and biological. The blood-based test for CRC reported in this study would have the effect of reducing such bias, thus potentially increasing detection rates for right sided lesions.

This pre-screening test is mainly intended for detection of TNM I to TNM III patients. For these patients, test sensitivity is $76 \%$ for left-sided cancers and $84 \%$ for right-sided cancers. TNM IV stage patients are likely to be diagnosed by conventional means and are less likely to benefit much from intervention.

\section{Conclusion}

This study finds that detection of CRCs using mRNA biomarkers from whole blood is equally sensitive to treatable TNM I - III lesions located throughout the colon (Figure 2). These findings support the use of the seven-gene panel as a non-biased method for CRC detection for both left and right-sided lesions.

\section{Abbreviations \\ CRC: Colorectal cancer; BMI: Body mass index; AUC ROC: Area under the receiver-operating-characteristic curve.}

\section{Competing interests}

Samuel Chao, Gailina Liew and Choong Chin Liew are all employed by GeneNews Ltd, Ontario, Canada, who funded this study. Gailina Liew is President and COO and Choong Chin Liew is Chief Scientist of GeneNews; Wayne Marshall was CEO of the company when the research was carried out. Robert Burakoff has no competing interests to declare.

\section{Authors' contributions}

CCL, WM and RB conceived and designed the study; SC and JY provided data analysis; GL and SC drafted the manuscript. All authors read and approved the final manuscript.

\section{Author details}

${ }^{1}$ GeneNews Ltd, 2 East Beaver Creek Road, Building 2, Richmond Hill, Ontario, Canada. ${ }^{2}$ University Health Network, Toronto Western Hospital, Toronto, Ontario, Canada. ${ }^{3}$ Brigham and Women's Hospital, Gastrointestinal Division, Harvard Medical School, Boston, MA, USA.

Received: 29 April 2013 Accepted: 17 July 2013

Published: 23 July 2013

\section{References}

1. American Cancer Society: Cancer facts and figures 2013. [http://www.cancer. org/acs/groups/content/@epidemiologysurveilance/documents/document/ acspc-036845.pdf].

2. Canadian Cancer Society: Colorectal cancer statistics. [http://www.cancer.ca/ en/cancer-information/cancer-type/colorectal/statistics/?region=on].

3. Winawer SJ, Zauber AG, Ho MN, O'Brien MJ, Gottlieb LS, Sternberg SS, Waye JD, Schapiro M, Bond JH, Panish JF, Ackroyd F, Shike M, Kurtz RC, HornsbyLewis L, Gerdes H, Stewart ET, National Polyp Study Workgroup: Prevention of colorectal cancer by colonoscopic polypectomy. N Eng J Med 1993, 329:1977-1981.

4. Baxter NN, Goldwasser MA, Paszat LF, Saskin R, Urbach DR, Rabeneck L: Association of colonoscopy and death from colorectal cancer. Ann Intern Med 2009, 150:1-8.
5. Singh H, Nugent Z, Demers AA, Kliewer EV, Mahmud SM, Bernstein CN: The reduction in colorectal cancer mortality after colonoscopy varies by site of the cancer. Gastroenterol 2010, 139:1128-1137.

6. Brenner $\mathrm{H}$, Hoffmeister M, Arndt V, Stegmaier C, Altenhofen L, Haug U: Protection from right- and left-sided colorectal neoplasms after colonoscopy: population-based study. J Natl Cancer Inst 2010, 102:89-95.

7. Brenner H, Chang-Claude J, Seiler CM, Rickert A, Hoffmeister M: Protection from colorectal cancer after colonoscopy: a population-based, casecontrol study. Ann Intern Med 2011, 154:22-30.

8. Soetikno RM, Kaltenbach T, Rouse RV, Park W, Maheshwari A, Sato T, Matsui S, Friedland S: Prevalence of nonpolypoid (flat and depressed) colorectal neoplasms in asymptomatic and symptomatic adults. JAMA 2008, 299:1027-1035.

9. Azzoni C, Bottarelli L, Campanini N, Di Cola G, Bader G, Mazzeo A, Salvemini C, Morari S, Di Mauro D, Donadei E, Roncoroni L, Bordi C, Sarli L: Distinct molecular patterns based on proximal and distal sporadic colorectal cancer: arguments for different mechanisms in the tumorigenesis. Int $J$ Colorect Dis 2007, 22:115-126.

10. Marshall KW, Mohr S, Khettabi FE, Nossova N, Chao S, Bao W, Ma J, Li XJ, Liew CC: Blood-based biomarker panel for stratifying current risk for colorectal cancer. Int J Cancer 2010, 126:1177-1186.

11. Greene FL, Page DL, Fleming ID, Fritz A, Balch CM, Haller DG, Morrow M (Eds): AJCC cancer staging manual. 6th edition. New York: Springer; 2002.

12. Vanburen P, Ma J, Chao S, Mueller E, Schneider DJ, Liew CC: Blood gene expression signatures associate with heart failure outcomes. Physiol Genomics 2011, 43:392-397.

13. Burakoff R, Hande S, Ma J, Banks PA, Friedman S, Makrauer F, Liew CC: Differential regulation of peripheral leukocyte genes in patients with active Crohn's disease and Crohn's disease in remission. J Clin Gastroenterol 2010, 44:120-126.

14. Burakoff R, Chao S, Perencevich M, Ying J, Friedman S, Makrauer F, Odze R, Khurana H, Liew CC: Blood-based biomarkers can differentiate ulcerative colitis from Crohn's disease and noninflammatory diarrhea. Inflamm Bowel Dis 2011, 17:1719-1725.

15. Tsuang MT, Nossova N, Yager T, Tsuang MM, Guo SC, Shyu KG, Glatt SJ, Liew CC: Assessing the validity of blood-based gene expression profiles for the classification of schizophrenia and bipolar disorder: a preliminary report. Am J Med Genet B Neuropsychiatr Genet 2005, 133B:1-5.

16. Glatt SJ, Everall IP, Kremen WS, Corbeil J, Sásik R, Khanlou N, Han M, Liew CC, Tsuang MT: Comparative gene expression analysis of blood and brain provides concurrent validation of SELENBP1 up-regulation in schizophrenia. Proc Natl Acad Sci USA 2005, 102:15533-15538.

17. Glatt SJ, Stone WS, Nossova N, Liew CC, Seidman LJ, Tsuang MT: Similarities and differences in peripheral blood gene-expression signatures of individuals with schizophrenia and their first-degree biological relatives. Am J Med Genet B Neuropsychiatr Genet 2011, 156B:869-887.

18. Osman I, Bajorin DF, Sun TT, Zhong H, Douglas D, Scattergood J, Zheng R, Han M, Marshall KW, Liew CC: Novel blood biomarkers of human urinary bladder cancer. Clin Cancer Res 2006, 12:3374-3380.

19. Liong ML, Lim CR, Yang H, Chao S, Bong CW, Leong WS, Das PK, Loh CS, Lau BE, Yu CG, Ooi EJJ, Nam RK, Allen PD, Steele GS, Wassmann K, Richie JP, Liew CC: Blood-based biomarkers of aggressive prostate cancer. PLOS One 2012, 7:e45802.

20. Zaatar AM, Lim CR, Bong CW, Lee MML, Ooi JJ, Suria D, Raman R, Chao S, Yang $\mathrm{H}$, Neoh SB, Liew CC: Whole blood transcriptome correlates with treatment response in nasopharyngeal carcinoma. J Exp Clin Cancer Research 2012, 31:76.

21. von Wagner C, Good A, Smith SG, Wardle J: Responses to procedural information about colorectal cancer screening using faecal occult blood testing: the role of consideration of future consequences. Health Expect 2011, 15:176-186.

22. de Wijkerslooth TR, de Haan MC, Stoop EM, Bossuyt PM, Thomeer M, van Leerdam ME, Essink-Bot ML, Fockens P, Kuipers EJ, Stoker J, Dekker E: Reasons for participation and nonparticipation in colorectal cancer screening: a randomized trial of colonoscopy and CT colonography. Am J Gastroenterol 2012, 107:1777-1783.

23. Klabunde CN, Vernon SW, Nadel MR, Breen N, Seeff LC, Brown ML: Barriers to colorectal cancer screening: a comparison of reports from primary care physicians and average-risk adults. Medical Care 2005, 43:939-944

24. Vernon SW: Participation in colorectal screening: a review. JNCI 1997 89:1406-1422. 
25. Worthley DL, Cole SR, Esterman A, Mehaffy S, Roosa NM, Smith A, Turnbull D, Young GP: Screening for colorectal cancer by faecal occult blood test: why people choose to refuse. Intern Med J 2006, 36:607-610.

26. Lewis SF, Jensen NM: Screening sigmoidoscopy. Factors associated with utilization. J Gen Intern Med 1996, 11:542-544.

27. Colorectal Association of Canada: Screening and diagnostics. A guide to screening tests. [http://www.colorectal-cancer.ca/en/screening/screening-tests].

doi:10.1186/1756-9966-32-44

Cite this article as: Chao et al:: Blood RNA biomarker panel detects both left- and right-sided colorectal neoplasms: a case-control study. Journal of Experimental \& Clinical Cancer Research 2013 32:44.

\section{Submit your next manuscript to BioMed Central and take full advantage of:}

- Convenient online submission

- Thorough peer review

- No space constraints or color figure charges

- Immediate publication on acceptance

- Inclusion in PubMed, CAS, Scopus and Google Scholar

- Research which is freely available for redistribution 